\title{
Bread type intake is associated with lifestyle and diet quality transition among Bedouin Arab adults
}

\author{
Kathleen Abu-Saad*, Iris Shai, Vered Kaufman-Shriqui, Larissa German, Hillel Vardi and Drora Fraser \\ S. Daniel Abraham International Center for Health and Nutrition, Department of Epidemiology and Health Services Evaluation, \\ Faculty of Health Sciences, Ben-Gurion University of the Negev, Beer-Sheva, Israel
}

(Received 12 January 2009 - Revised 8 May 2009 - Accepted 13 May 2009 - First published online 7 July 2009)

The traditionally semi-nomadic Bedouin Arabs in Israel are undergoing urbanisation with concurrent lifestyle changes, including a shift to using unfortified white-flour bread instead of wholewheat bread as the main dietary staple. We explored associations between the transition from wholewheat to white-flour bread and (1) lifestyle factors, (2) overall diet quality, and (3) health status. We conducted a nutrition survey among 451 Bedouin adults, using a modified $24 \mathrm{~h}$ recall questionnaire. Bread intake accounted for $32.7 \%$ of the total energy intake. Those consuming predominantly white bread (PWB) (n 327) were more likely to be urban (OR 2.79; $95 \%$ CI 1.70, 4.58), eating store-bought rather than homemade bread (OR 8.18; $95 \%$ CI 4.34, 15.41) and currently dieting (OR 4.67; $95 \%$ CI 1.28, 17.11) than those consuming predominantly wholewheat bread (PWWB) ( $n$ 124). PWB consumption was associated with a lower intake of dietary fibre $(23.3$ (SE 0.6$) v .41 \cdot 8$ (SE 1.0$) \mathrm{g} / \mathrm{d} ; P \leq 0 \cdot 001)$, a higher intake of saturated fats $(26.9 v .24 .6 \%$ of total fat; $P=0.013)$ and lower intakes of Fe (11.0 (SE 0.3$) v .16 .7$ (SE 0.4) $\mathrm{mg} / \mathrm{d}), \mathrm{Mg}(262.2(\mathrm{SE} 5.9) v$. 490.3 (SE 9.8) mg/d), vitamin E (6.5 (SE 0.2) v. 8.6 (SE 0.3) mg/d) and most B vitamins than PWWB consumption $(P<0.001$ for all), after adjusting for total energy intake. Among those aged $\geq 40$ years, PWB consumption was associated with a 9.85-fold risk $(95 \%$ CI $2 \cdot 64,36 \cdot 71 ; P=0 \cdot 001)$ of having one or more chronic conditions, as compared with PWWB consumption, after controlling for other risk factors. White bread intake was associated with a less traditional lifestyle and poorer diet quality, and may constitute a useful marker for at-risk subgroups to target for nutritional interventions.

Nutrition transition: Whole-wheat intake: Diet quality: Bedouin Arabs

Bedouin Arabs living in the Negev Desert in southern Israel were traditionally a semi-nomadic population ${ }^{(1)}$ who, during the past 60 years, have been undergoing a process of sedentarisation and urbanisation ${ }^{(2,3)}$. Similar to many indigenous populations in industrialised countries, and the populations of developing countries, the Bedouin are experiencing a nutrition transition characterised by the replacement of traditional diets with diets higher in refined and processed foods, and the dual burdens of under- and over-nutrition ${ }^{(4,5)}$.

Historically, the Negev Bedouin were semi-nomadic agropastoralists. Due to regional economic development, they began to engage in wage labour in the 1940s, but agropastoralism was the mainstay of their economy ${ }^{(3)}$. From Israel's establishment in 1948 to 1966, Bedouin mobility was restricted to a designated reservation area, and this largely eliminated their access to wage labour jobs. The restrictions led to spontaneous sedentarisation, and increased their dependence upon localised agro-pastoralism ${ }^{(3,6)}$. The primary crop raised was wheat, from which their traditional dietary staple of high-extraction wholewheat flour bread was made. This staple food comprised $50-60 \%$ of their total energy intake, since it formed the basis of most dishes in the diet, or alternatively, was used as the utensil for eating other foods from common plates ${ }^{(1,2)}$. This lifestyle entailed a high level of physical activity, and in the 1960s anthropometric ${ }^{(1)}$ and clinical ${ }^{(7)}$ data on Bedouin adults indicated that the BMI for men and women were about 21.3 and $21.4 \mathrm{~kg} / \mathrm{m}^{2}$, and that rates of hypertension and diabetes among those aged $\geq 30$ years were 3.2 and $2.5 \%$, respectively.

In the mid- to late-1960s, the government ended the restrictions on Bedouin mobility, and began establishing nonagricultural, urban-style settlements for this population ${ }^{(3,6)}$. As a consequence of these changes, the Bedouin gradually became dependent upon integration in the modern Israeli labour market for their subsistence. Though not all Bedouin moved to the towns, most agricultural and herding activities ended, while access to markets and modern amenities (for example, motor vehicles; and for the urbanised, electricity, refrigeration, etc) improved ${ }^{(2,3,8)}$. The lifestyle changes also included exposure to a range of Western foods resulting from increased commerce and interchange with the surrounding, more Westernised environment. New foods have entered the Bedouin diet to varying extents ${ }^{(9)}$ and have replaced traditional foods; however, quantitative data are scant and

Abbreviations: AMDR, acceptable macronutrient distribution range; BNS, Bedouin Nutrition Study; PAL, physical activity level; PWB, predominantly white bread; PWWB, predominantly wholewheat bread.

* Corresponding author: Dr Kathleen Abu-Saad, fax +972 8647 7637, email kathline@bgu.ac.il 
thus do not clarify the nature, extent or effect of these changes. During this same period, chronic disease prevalence has increased dramatically as compared with that reported in the 1960s. According to recently published data from the medical records of the Clalit Health Maintenance Organisation (HMO) serving over $85 \%$ of the Bedouin population ${ }^{(10)}$, rates of diagnosed hypertension and diabetes have reached 21.0 and $16.9 \%$, respectively, among those aged $\geq 40$ years $^{(11,12)}$.

These processes of change gave us our a priori hypothesis that bread type consumption may be associated with lifestyle and dietary transition, and could be used to track that transition and its effect on diet quality and health. Therefore, in the Bedouin Nutrition Study (BNS), we set out to explore the associations between predominantly wholewheat bread (PWWB) v. predominantly white bread (PWB) intake and lifestyle and dietary/diet quality changes, and possible health consequences among Bedouin undergoing this transition.

\section{Methods}

\section{Bedouin population background}

The Bedouin lifestyle before 1948 through the 1960s has been described in detail elsewhere ${ }^{(1,2)}$. Briefly, they raised seasonal, rain water-dependent crops (primarily wheat, barley and lentils), and engaged in semi-nomadic animal husbandry, maintaining herds of sheep, goats and camels ${ }^{(1,2,8)}$. This lifestyle required a high level of physical activity from men, women and children. In addition to herding, animal care, and agriculture, it involved transporting water, gathering fuel, processing and preserving traditional dairy and other agricultural products, food production (for example, slaughtering livestock for meat, making bread), utilising wool and goat hair to weave carpets and tents, and make other household items, and a great deal of walking, as other means of transportation were limited ${ }^{(1,2)}$. In the late $1960 \mathrm{~s}$, the government began establishing urban-style settlements for the Bedouin, which were parcelled into $1000 \mathrm{~m}^{2}$ lots for the construction of residential housing. These towns supplied modern amenities such as running water, electricity, telephone services, and local stores, health clinics and schools, but few local employment opportunities, so some Bedouin did not agree to move to the towns ${ }^{(3,6)}$. When the BNS was conducted (2001-3), the Negev Bedouin population numbered 138000 , of whom about $60 \%$ lived in government-planned towns ${ }^{(13)}$. The remaining $40 \%$ lived more traditionally in unrecognised villages not connected to central infrastructures for water, electricity and land-line telephone services, and highway networks. The socio-economic status of the Negev Bedouin, as measured by education and income levels, remains the lowest of any population group in Israel ${ }^{(13,14)}$.

\section{Study design}

The BNS has been described elsewhere ${ }^{(15,16)}$. The study was conducted with the aim of obtaining dietary intake data for Bedouin adults in the Negev. The use of standard methods for drawing a random sample (for example, street addresses from voter registration lists, telephone directories, etc) would have systematically excluded those living in settings that lacked official mapping/street addresses and land-line telephones (about $40 \%$ of the population). To obtain a sample that included Bedouin from both recognised and unrecognised localities, we drew the study population from Bedouin adults visiting family members at the Soroka University Medical Center, the only regional hospital serving the southern (Negev) region of Israel, and adults accompanying children attending the prenatal/preventive care Ministry of Health Maternal and Child Health Care clinics in Bedouin towns. These settings provided us with access to a broad, inclusive cross-section of the population because the regional hospital and clinics in the towns serve both the local municipal residents and residents of the surrounding unrecognised villages, and these healthcare services are provided free (curative services) or for a low, nominal cost (preventive services) to all citizens by law.

We used the PEPI v. 3 software (Brixton Health, Llanidloes, Powys, UK; http://www.brixtonhealth.com) to calculate the sample size, according to the number of participants needed to reliably estimate protein intake. The calculation was based on the size of the Bedouin population aged $\geq 19$ years (about 47000 in 2000) ${ }^{(17)}$, and a standard deviation for the estimate of protein intake similar to that reported for the Jewish population in the Negev $(33 \mathrm{~g} / \mathrm{d})^{(18)}$, with a CI of $\pm 3 \mathrm{~g} / \mathrm{d}$, which yielded a required sample size of 463 . Since even at the upper end of the CI, the relative standard error of the protein estimate was $5 \%$, which is well below the statistical criterion of a relative standard error $>25 \%$ used by the National Health and Nutrition Examination Survey (NHANES) to define unreliable nutrient estimates ${ }^{(19)}$, we sought to recruit a sample of between 450 and 500 adults. Bedouin adults (aged $\geq 19$ years) accompanying patients or children who were waiting for services were invited to participate in the study. Response rates were high (91\%), as waiting times in these facilities tend to be quite long. The primary reason for refusal was insufficient time before the appointment.

Arabic-speaking interviewers familiar with the Bedouin culture interviewed 519 participants. We excluded forty-five interviews obtained during the Islamic month of Ramadan, which involves fasting from sunrise until sunset, and another twenty-three questionnaires that contained intake data of $<3347$ or $>17573 \mathrm{~kJ}(<800$ or $>4200 \mathrm{kcal})$ for men, and $<2510$ or $>14644 \mathrm{~kJ}(<600$ or $>3500 \mathrm{kcal})$ for women ${ }^{(20)}$. This resulted in a sample of 451 participants who were included in the analysis.

\section{Common-plate dietary assessment and food database}

We used a modified US Department of Agriculture $24 \mathrm{~h}$ recall questionnaire $^{(15,21)}$, which was validated for use in Israel ${ }^{(22)}$, and the standardised five-pass method ${ }^{(23)}$ to obtain dietary intake data. That questionnaire was further adapted to capture the traditional dietary habits of the Bedouin population that involve eating meals from common serving dishes ${ }^{(15,16)}$. In meals eaten with bread, a bite-sized piece of bread is torn from the pita or bread and serves as a single-use utensil for taking food from common plates (with which it is consumed). This results in a very high bread intake. Since many of the foods served in common plates are sauce-like, or liquid, it is not possible for a person eating with others to visualise how much he/she consumed from the common plate. In other 
meals, the food is served on a large platter around which everyone sits, and the rules of hygiene require that each person eats from the part of the platter directly in front of him/her. A full description of the modification process of the $24 \mathrm{~h}$ recall for common-plate eating can be found elsewhere $^{(15)}$. Briefly, for foods eaten with bread from common plates shared with other diners, the interviewer asked respondents how much bread they ate during the meal, and the relative amount eaten ( smaller $=1$, medium/approximately equal $=2$, larger $=3$ ) from each of the common-plate dishes, and the bread intake was partitioned accordingly among the common-plate dishes. The method for calculating the portion size consumed from each common-plate dish was based on weighed records (obtained under natural eating conditions from adults in rural and urban Bedouin households), from which we determined the 'carrying capacity' of bread for foods of different consistencies. The weight records, expressed as $\mathrm{g}$ common-plate dish per $\mathrm{g}$ bread, were grouped according to foods with similar consistencies into a range of food:bread ratios, and were used, together with the amount of bread apportioned to each common-plate dish, to calculate the amount of commonplate food consumed (Fig. 1). For meals eaten from a single large common platter, pictures with different relative portions removed from the platter were used as reporting aids. Quasivalidation of the energy intake data were conducted by comparing estimated energy requirements, based on BMR and reported physical activity levels (PAL), with reported energy intake, and was found to be well within the range of values reported for the original US Department of Agriculture $24 \mathrm{~h}$ recall in a variety of populations ${ }^{(15)}$.

Trained Arabic-speaking interviewers conducted the interviews in Arabic using a modified US Department of Agriculture instruction manual for different food types and a food models/portion-size booklet that included common Israeli and Bedouin foods, utensils and portion sizes. As instructed in the $24 \mathrm{~h}$ recall interview manual, interviewers obtained information on whether foods were commercially prepared or homemade. In particular, they determined whether bread was store-bought or homemade, as well as the specific type of bread, and flour used.

We derived the nutrient values ${ }^{(24)}$ for all survey foods and ingredients using the food composition tables of the S. Daniel Abraham International Center for Health and Nutrition which are based on US Department of Agriculture Release SR19, modified to include Israeli manufactured foods, common Israeli recipes ${ }^{(18)}$, and traditional Bedouin foods and recipes ${ }^{(15)}$. Trained nutritional data entry coders used our computer system to enter data into the database. Recipes were calculated using another computer system develped at the Center based on the concept of the Amercian Food Information Analysis System (FIAS) program ${ }^{(18,25)}$.

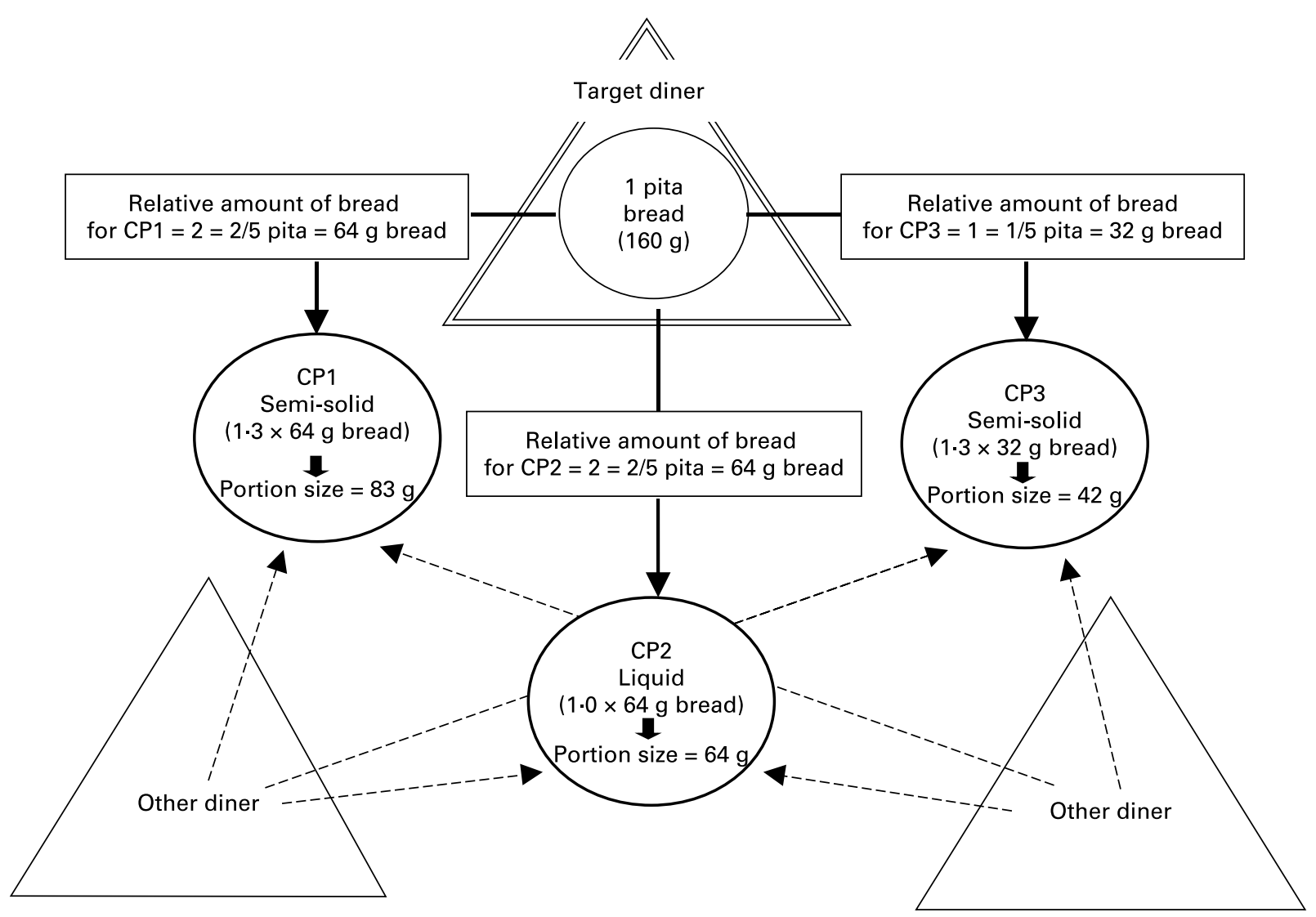

Fig. 1. Example of estimating individual intake for the 'target diner' from foods eaten with bread from common plates shared with other diners, where the target diner's bread was divided approximately equally (relative amount $=2$ ) between common-plate dish $1(\mathrm{CP} 1)$ and common-plate dish $2(\mathrm{CP} 2)$, and less (relative amount $=1$ ) was used to eat from common-plate dish $3(\mathrm{CP} 3)$. The weight of bread used with each dish (g) is multiplied by the food:bread ratio of the dish $(1.3$ for semi-solid; 1.0 for liquid) to obtain a portion size of $83 \mathrm{~g}$ for CP1, $64 \mathrm{~g}$ for CP2 and $42 \mathrm{~g}$ for CP3. 


\section{Quality control}

Quality control was applied at four stages. First, each interview was checked for missing data within $1-3 \mathrm{~d}$ of the interview. Second, after data entry, the BNS study coordinator, who had extensive knowledge of Bedouin foods and the process for quantifying intake from common plates, reviewed each questionnaire for accurate data entry and appropriate application of the common-plate quantification method. Requests for corrections were then returned to the coders, and re-checked. At the third stage, registered dietitians reviewed each questionnaire, returned corrections to the coders, and re-checked corrected data entries; and, at the final stage, the BNS study coordinator and registered dietitians made cross-interview checks to detect unusual nutrient or food model values.

\section{Bread group definition}

As bread is the main staple in the Bedouin diet, we used it to classify dietary change in the population. Bread was coded according to the production process (for example, store-bought or homemade), specific bread type, and flour used. We used the bread codes to divide bread intake into two types based on the flour used: (1) wholewheat flour bread, including homemade wholewheat pita and traditional unleavened bread, and store-bought wholewheat loaf bread, rolls and buns; (2) white-flour bread, including store-bought and homemade white-flour pita and unleavened bread, and commercially produced white-flour loaf bread, rolls and buns. We then divided the population into two bread groups: (1) those with a PWWB intake pattern, who ate most of their meals (two or more) with wholewheat bread; (2) those with a PWB intake pattern, who ate white bread or other refined carbohydrates (for example, white rice) with most of their meals (two or more). Respondents who did not eat any bread, who reported eating white rice or pasta instead, were also included in this category.

\section{Sociodemographic, health status and physical activity information}

Upon completion of the $24 \mathrm{~h}$ recall, the interviewers asked respondents a number of demographic and health status questions, including: place of residence (Bedouin town $=$ urban, unrecognised village/area = rural); current employment status (employed, unemployed) and occupation; whether they currently smoked (yes, no) and if so, number of cigarettes per d; whether they were currently following a medically prescribed or other diet, and if so, what type (low-fat, low-sugar, low-salt, weight-loss, other); number of years of schooling. Regarding health status, we collected data on chronic disease prevalence in the sample by asking respondents, 'Have you ever been told you have (chronic disease/condition) by a physician?'; for diabetes, we excluded gestional diabetes. The respondents' weight (in light street clothing) and height were measured, using a portable digital scale and collapsible measuring stick. We used a physical activity questionnaire based upon a synthesis of previously validated international questionnaires $^{(26,27)}$, and modified for use in Israel ${ }^{(28)}$, to assess PAL. It included questions about the time spent in and intensity of work, recreational, leisure-time and household activities, and was further modified to capture specific activities associated with Bedouin lifestyle (for example, herding, washing clothes by hand). The definitions of the joint FAO, WHO and United Nations University report on human energy requirements ${ }^{(29)}$ were used to classify physical activities as: sedentary/light (non-strenuous occupations, no regular leisure-time or lifestyle-required physical exercise); active/ moderately active (moderate occupational exertion or moderate/vigorous leisure activity $\geq 1 \mathrm{~h} / \mathrm{d}$ ); or vigorously active (very strenuous occupational or leisure activities several hours per d).

\section{Statistical analysis}

We examined the sociodemographic and health status of the BNS participants by bread intake group. In univariate analyses, we compared the sample by bread intake group (PWB, PWWB) and chronic disease prevalence (yes, no) for categorical variables using $\chi^{2}$ tests, and for continuous variables using $t$ tests. Variables from univariate analyses resulting in $P<0.10$ were considered for inclusion in multivariate logistic regression. Independent variables were entered using the backward stepwise method to identify the model with the best goodness-of-fit ( $-2 \log$ likelihood). We used general linear models to compare nutrient intakes by bread group. Since micronutrient values were not normally distributed, they were transformed using the natural log transformation. We also used general linear models to compare nutrient intakes by bread group with sex- and age-specific dietary reference intake parameters of the US Institute of Medicine ${ }^{(30)}$, which are the reference parameters most commonly used. Macronutrient intakes were evaluated according to the acceptable macronutrient distribution range (AMDR; range of intakes associated with reduced risk of chronic disease while allowing for adequate intakes of essential nutrients). Micronutrient intakes were evaluated against the recommended daily allowance (i.e. average daily dietary nutrient level sufficient to meet the nutrient requirement of $97-98 \%$ of healthy individuals in specified life-stage and sex group). For the micronutrients for which the recommended daily allowance parameters have not been determined due to insufficient evidence, intakes were evaluated against the adequate intake parameters (average daily intake level that assumed to be adequate based on experimentally determined approximations/estimates). We conducted all statistical analyses using SPSS (version 14.0; SPSS Inc., Chicago, IL, USA), using $P<0.05$ to indicate statistical significance.

The present study was conducted according to the guidelines laid down in the Declaration of Helsinki and all procedures involving human subjects were approved by the Soroka University Medical Center Helsinki Committee. Verbal informed consent was obtained from all participants, and was witnessed and formally recorded.

\section{Results}

Table 1 presents selected population characteristics of the study participants by bread group. Most respondents $(72.5 \%)$ reported a PWB intake pattern. Participants in the PWB group were more likely to be urbanised, better educated, 
Table 1. Comparison of selected population characteristics between predominantly wholewheat bread (PWWB) v. predominantly white bread (PWB) consumers among the Bedouin Nutrition Study population

(Numbers of subjects and percentages or mean values and standard deviations)

\begin{tabular}{|c|c|c|c|c|c|c|c|}
\hline \multirow[b]{3}{*}{ Characteristics } & & & \multicolumn{4}{|c|}{ Bread intake groups } & \multirow[b]{3}{*}{$P^{\star}$} \\
\hline & \multicolumn{2}{|c|}{ Total ( $n$ 451) } & \multicolumn{2}{|c|}{$\begin{array}{c}\text { PWWB } \\
\text { (n 124; } 27 \%)\end{array}$} & \multicolumn{2}{|c|}{$\begin{array}{c}\text { PWB } \\
\text { (n } 327 ; 73 \%)\end{array}$} & \\
\hline & $n$ & $\%$ & $n$ & $\%$ & $n$ & $\%$ & \\
\hline Sex, women & 302 & $67 \cdot 0$ & 75 & 60.5 & 227 & 69.4 & 0.072 \\
\hline Age $\geq 40$ years & 102 & $22 \cdot 7$ & 31 & $25 \cdot 0$ & 71 & $21 \cdot 8$ & 0.466 \\
\hline Urban residence & 293 & $65 \cdot 0$ & 57 & $46 \cdot 0$ & 236 & $72 \cdot 2$ & $<0.001$ \\
\hline Employed & 102 & $22 \cdot 6$ & 20 & $16 \cdot 1$ & 82 & $25 \cdot 1$ & 0.043 \\
\hline Current smokers & 93 & $20 \cdot 7$ & 35 & $28 \cdot 2$ & 58 & $17 \cdot 8$ & 0.015 \\
\hline Currently dieting & 35 & $7 \cdot 8$ & 3 & 2.5 & 32 & $9 \cdot 8$ & 0.010 \\
\hline Sedentary/light physical activity level & 389 & $86 \cdot 3$ & 109 & 87.9 & 280 & $85 \cdot 6$ & 0.531 \\
\hline Store-bought bread at one or more meals & 184 & $40 \cdot 8$ & 17 & $13 \cdot 7$ & 167 & $51 \cdot 1$ & $<0.001$ \\
\hline \multicolumn{8}{|l|}{ Self-reported chronic diseasest } \\
\hline Hypercholesterolaemia & 19 & $18 \cdot 8$ & 2 & 6.5 & 17 & $24 \cdot 3$ & 0.034 \\
\hline Hypertension & 26 & $25 \cdot 7$ & 5 & $16 \cdot 1$ & 21 & $30 \cdot 0$ & 0.141 \\
\hline Diabetes & 16 & $15 \cdot 7$ & 2 & $6 \cdot 5$ & 14 & $19 \cdot 7$ & 0.090 \\
\hline Chronic heart disease (CHD) & 3 & $4 \cdot 2$ & 0 & 0.0 & 3 & 6.5 & 0.549 \\
\hline Any of the above & 38 & $37 \cdot 3$ & 5 & $16 \cdot 1$ & 33 & $46 \cdot 5$ & 0.004 \\
\hline Age (years) & & & & & & & 0.474 \\
\hline Mean & \multicolumn{2}{|c|}{33.8} & \multicolumn{2}{|c|}{$34 \cdot 3$} & \multicolumn{2}{|c|}{33.6} & \\
\hline SD & \multicolumn{2}{|c|}{$10 \cdot 3$} & \multicolumn{2}{|c|}{$10 \cdot 2$} & \multicolumn{2}{|c|}{$10 \cdot 4$} & \\
\hline Education (years) $\ddagger$ & & & & & & & 0.003 \\
\hline Mean & \multicolumn{2}{|c|}{8.4} & \multicolumn{2}{|c|}{$7 \cdot 3$} & \multicolumn{2}{|c|}{$9 \cdot 0$} & \\
\hline SD & \multicolumn{2}{|c|}{4.0} & \multicolumn{2}{|c|}{4.4} & \multicolumn{2}{|c|}{3.8} & \\
\hline $\mathrm{BMI}\left(\mathrm{kg} / \mathrm{m}^{2}\right)$ & & & & & & & 0.139 \\
\hline Mean & \multicolumn{2}{|c|}{$26 \cdot 0$} & \multicolumn{2}{|c|}{$26 \cdot 5$} & \multicolumn{2}{|c|}{$25 \cdot 8$} & \\
\hline SD & \multicolumn{2}{|c|}{4.7} & \multicolumn{2}{|c|}{4.9} & \multicolumn{2}{|c|}{4.5} & \\
\hline Energy from bread (\%) & & & & & & & $<0.001$ \\
\hline Mean & \multicolumn{2}{|c|}{32.7} & \multicolumn{2}{|c|}{$38 \cdot 6$} & \multicolumn{2}{|c|}{30.4} & \\
\hline SD & & & & & & & \\
\hline Energy from wholewheat bread (\%) & & & & & & & $<0.001$ \\
\hline Mean & & & & & & & \\
\hline SD & & & & & & & \\
\hline Energy from white bread (\%) & & & & & & & $<0.001$ \\
\hline Mean & & & & & & & \\
\hline SD & & & & & & & \\
\hline
\end{tabular}

${ }^{*}$ For categorical variables, $P$ for $\chi^{2}$ test; for continuous variables, $P$ for $t$ test.

$\dagger$ Among those aged $\geq 40$ years $(n 102)$.

$\ddagger$ Data available for a subsample of 70 and 157 , respectively.

employed, non-smokers and currently following a diet than those in the PWWB group. PAL did not differ by bread group, being sedentary/light for most respondents $(86 \cdot 3 \%)$ and moderate for the remainder $(13.7 \%)$. Only small proportions of the participants continued to engage in traditional physical activities, such as herding (3.8\%), animal care $(8.9 \%)$, routinely hand-washing clothes $(8.8 \%)$, etc; and this differed significantly by rural/urban status, but not by bread group (data not shown). Most respondents who were dieting were on weight-loss diets $(74.2 \%)$, with smaller numbers on fat-, salt- or sugar-restricted diets.

Nearly all $(97.6 \%)$ reported eating bread, and the median number of meals eaten with bread per d was 2 (range $0-5$ ). Mean bread intake accounted for $32.7 \%$ of the energy intake for the sample as a whole. Over one-third of the energy intake of the PWWB group came from wholewheat bread, as compared with $5.2 \%$ among the PWB group; and the reverse was observed for the percentage of energy obtained from white bread (Table 1). Of the wholewheat bread consumed, $97.7 \%$ was homemade, while only $49.0 \%$ of the white bread consumed was homemade. Participants with PWB intake obtained a lower percentage of their total energy from bread than those with PWWB intake, and were much more likely to consume store-bought rather than homemade bread.

Due to possible confounding among the demographic/ population variables vis-à-vis the association with bread type intake, we used a multivariate logistic regression model to examine their independent contribution to being PWB $v$. PWWB consumers. The model included rural/urban status, employment, smoking, dieting, percentage of total energy from bread, and store-bought bread consumption, and was further adjusted for sex, age group, BMI category and PAL (sedentary/light, moderate) (Table 2). Urban $v$. rural residence was associated with a $2 \cdot 8$-fold likelihood of belonging to the PWB group; while dieters $v$. non-dieters and those eating store-bought $v$. homemade bread had a $4 \cdot 7$-fold and 8.2-fold likelihood of being in the PWB group, respectively. All of these associations suggest that PWB consumption is characterised by a more Westernised lifestyle than PWWB 
Table 2. Results from a multivariate logistic regression analysis of the characteristics associated with predominantly white bread (PWB) intake $v$. predominantly wholewheat bread (PWWB) intake pattern among the Bedouin Nutrition Study population* (Adjusted odds ratios and $95 \%$ confidence intervals)

\begin{tabular}{|c|c|c|c|}
\hline Variables in the model & Adjusted OR & $95 \% \mathrm{Cl}$ & $P$ \\
\hline Female $v$. male & 1.45 & $0.66,3 \cdot 16$ & 0.353 \\
\hline Urban $v$. rural residence & $2 \cdot 79$ & $1 \cdot 70,4 \cdot 58$ & $<0.001$ \\
\hline Age $\geq 40$ years $v .<40$ years & 0.85 & $0.47,1.51$ & 0.574 \\
\hline Employed $v$. unemployed & 2.03 & $0.93,4.43$ & 0.077 \\
\hline Smoker v. non-smoker & 0.48 & $0.22,1.05$ & 0.068 \\
\hline Store-bought bread eaten at one or more meals $v$. no store-bought bread eaten & $8 \cdot 18$ & $4 \cdot 34,15 \cdot 41$ & $<0.001$ \\
\hline Currently dieting $v$. not dieting & 4.67 & $1 \cdot 28,17 \cdot 11$ & 0.020 \\
\hline \multicolumn{4}{|l|}{ BMI (reference: $<25.0 \mathrm{~kg} / \mathrm{m}^{2}$ ) } \\
\hline $25 \cdot 0-29 \cdot 9 \mathrm{~kg} / \mathrm{m}^{2}$ & 0.45 & $0.26,0.78$ & 0.004 \\
\hline$\geq 30 \cdot 0 \mathrm{~kg} / \mathrm{m}^{2}$ & 0.43 & $0.21,0.88$ & 0.020 \\
\hline PAL; moderate $v$. sedentary/light activity level & 0.83 & $0.37,1 \cdot 82$ & 0.635 \\
\hline Total energy from bread; $\geq$ median $\%(33 \%+) v .<$ median $\%(0-32 \%)$ & 0.48 & $0.29,0.80$ & 0.004 \\
\hline
\end{tabular}

PAL, physical activity level.

* PWB coded 1; PWWB coded 0.

consumption. PWWB intake patterns were associated with deriving a higher percentage of total energy from bread, and also with having a higher BMI.

In order to explore the diet quality changes associated with this dietary transition, as described by bread intake patterns, we examined the mean intake of selected nutrients by bread group, adjusted for age, sex, rural/urban status, PAL and (for micronutrients) energy intake. The results are presented in Table 3, along with the mean percentages of the dietary reference intake achieved by bread group. While in the PWWB group the daily total energy and macronutrient intakes were significantly higher than in the PWB group $(P<0.001)$, the groups did not differ in percentages of total energy from protein, carbohydrates and fat. The mean intakes of both

Table 3. Daily nutrient intake by bread intake groups defined as predominantly wholewheat bread (PWWB) and predominantly white bread (PWB) intake patterns*

(Mean values with their standard errors)

\begin{tabular}{|c|c|c|c|c|c|c|c|}
\hline \multirow[b]{2}{*}{ Nutrients } & \multicolumn{2}{|c|}{ PWWB (n 124) } & \multicolumn{2}{|c|}{ PWB (n 327) } & \multirow[b]{2}{*}{$P$} & \multicolumn{2}{|c|}{$\begin{array}{l}\text { Percentage of } \\
\text { DRI† }\end{array}$} \\
\hline & Mean & SE & Mean & SE & & PWWB & PWB \\
\hline Total energy (kJ/d) & 11459 & 276 & 8223 & 167 & $<0.001$ & & \\
\hline Protein $(\mathrm{g} / \mathrm{d})$ & 78.9 & $2 \cdot 7$ & $64 \cdot 1$ & 1.6 & $<0.001$ & & \\
\hline Energy from protein (\%) & $13 \cdot 9$ & 0.4 & $13 \cdot 6$ & 0.2 & 0.528 & 0.0 & 0.0 \\
\hline Fat $(g / d)$ & $72 \cdot 6$ & $3 \cdot 0$ & $56 \cdot 6$ & $1 \cdot 8$ & $<0.001$ & & \\
\hline Energy from fat (\%) & $27 \cdot 6$ & 0.8 & $26 \cdot 2$ & 0.5 & 0.144 & $16 \cdot 1$ & $13 \cdot 3$ \\
\hline SFA ( $\%$ total fat) & $24 \cdot 6$ & $0 \cdot 8$ & $26 \cdot 9$ & 0.5 & 0.013 & & \\
\hline MUFA ( $\%$ total fat) & 39.9 & 1.0 & 38.8 & 0.6 & 0.326 & & \\
\hline PUFA (\% total fat) & $27 \cdot 8$ & $1 \cdot 1$ & $27 \cdot 4$ & 0.7 & 0.762 & & \\
\hline Cholesterol (mg/d) & $194 \cdot 1$ & $17 \cdot 2$ & $190 \cdot 3$ & $10 \cdot 3$ & 0.671 & & \\
\hline Carbohydrates (g/d) & $373 \cdot 6$ & $10 \cdot 2$ & $308 \cdot 6$ & $6 \cdot 2$ & $<0.001$ & & \\
\hline Energy from carbohydrates (\%) & $62 \cdot 7$ & 0.9 & 61.9 & 0.5 & 0.566 & 31.5 & 39.1 \\
\hline Dietary fibre $(\mathrm{g} / \mathrm{d})$ & $41 \cdot 8$ & 1.0 & $23 \cdot 3$ & 0.6 & $<0.001$ & 140.5 & 79.1 \\
\hline $\mathrm{Ca}(\mathrm{mg} / \mathrm{d})$ & $428 \cdot 7$ & $20 \cdot 8$ & 391.5 & $12 \cdot 5$ & 0.081 & 41.8 & 38.4 \\
\hline $\mathrm{Fe}(\mathrm{mg} / \mathrm{d})$ & $16 \cdot 7$ & 0.4 & $11 \cdot 0$ & 0.3 & $<0.001$ & $130 \cdot 2$ & $87 \cdot 0$ \\
\hline$M g(m g / d)$ & $490 \cdot 3$ & $9 \cdot 8$ & $262 \cdot 2$ & 5.9 & $<0.001$ & $139 \cdot 2$ & $75 \cdot 3$ \\
\hline$K(g / d)$ & $3 \cdot 0$ & $0 \cdot 1$ & $2 \cdot 3$ & 0.0 & $<0.001$ & $63 \cdot 1$ & $49 \cdot 0$ \\
\hline $\mathrm{Zn}(\mathrm{mg} / \mathrm{d})$ & 11.6 & 0.3 & $8 \cdot 1$ & 0.2 & $<0.001$ & $113 \cdot 8$ & $79 \cdot 2$ \\
\hline Vitamin A ( $\mu \mathrm{g} R A E / d)$ & $453 \cdot 2$ & 288.8 & $677 \cdot 4$ & $172 \cdot 9$ & 0.743 & 54.7 & $82 \cdot 2$ \\
\hline Vitamin $E(\mathrm{mg} / \mathrm{d})$ & 8.6 & 0.3 & $6 \cdot 5$ & 0.2 & $<0.001$ & $57 \cdot 2$ & 43.1 \\
\hline Vitamin C $(\mathrm{mg} / \mathrm{d})$ & $92 \cdot 3$ & $6 \cdot 9$ & 88.0 & $4 \cdot 1$ & 0.237 & $106 \cdot 6$ & $101 \cdot 2$ \\
\hline Thiamin $(\mathrm{mg} / \mathrm{d})$ & 1.35 & 0.03 & 0.88 & 0.02 & $<0.001$ & $109 \cdot 1$ & 71.3 \\
\hline Vitamin $B_{2}$ (riboflavin) $(\mathrm{mg} / \mathrm{d})$ & 1.43 & 0.06 & 1.21 & 0.04 & $<0.001$ & 109.5 & $92 \cdot 6$ \\
\hline Niacin (mg/d) & $22 \cdot 0$ & 0.6 & $15 \cdot 3$ & 0.4 & $<0.001$ & $138 \cdot 0$ & $96 \cdot 2$ \\
\hline Vitamin $B_{6}(\mathrm{mg} / \mathrm{d})$ & 1.80 & 0.05 & 1.34 & 0.03 & $<0.001$ & $118 \cdot 8$ & 89.3 \\
\hline Folate $(\mu \mathrm{g} / \mathrm{d})$ & $290 \cdot 2$ & $13 \cdot 4$ & $275 \cdot 5$ & $8 \cdot 0$ & 0.144 & $63 \cdot 2$ & 60.5 \\
\hline
\end{tabular}


groups were within the AMDR for all macronutrients. None exceeded the upper end of the AMDR for protein (10-35\%); however, $2.4 \%$ of the PWWB group were below the lower end of the range, as compared with $14.4 \%$ of the PWB group $(P<0.001)$. Less than $20 \%$ of respondents exceeded the upper end of the AMDR for fat $(35 \%)$, while approximately one-third exceeded the upper end of the AMDR for carbohydrates $(65 \%)$. Most of the fat intake (about $75 \%$ ) came from MUFA or PUFA; however, the percentage of total fat from SFA was significantly lower in the PWWB than the PWB group $(P=0 \cdot 013)$. PWWB respondents exceeded, while on the average PWB respondents achieved less than $80 \%$ of, the adequate intake for dietary fibre.

The general linear model results showed significant differences between the PWWB and PWB groups in mean daily intakes of most micronutrients, after adjustment for energy intake, age, sex, rural/urban status and PAL (Table 3). The intakes of $\mathrm{Ca}, \mathrm{K}$, vitamin $\mathrm{A}$, vitamin $\mathrm{E}$ and folate were below the recommended daily allowance or adequate intake for all respondents, yet the intakes of most of these nutrients were significantly higher in the PWWB than the PWB group. PWWB respondents had higher intakes of $\mathrm{Fe}, \mathrm{Mg}$, $\mathrm{Zn}$, thiamin, vitamin $\mathrm{B}_{2}$, niacin and vitamin $\mathrm{B}_{6}(P<0.001)$ than PWB respondents, and, on average, PWWB respondents met or exceeded the recommended daily allowance for all of these nutrients, while PWB respondents fell below the recommended daily allowance.

To answer the question of whether this dietary transition, as described by the bread groups, may also affect health, we examined its association with reported chronic diseases (hypercholesterolaemia, hypertension, type 2 diabetes and CHD) in the sample. We conducted this analysis among participants aged $\geq 40$ years ( $n$ 102), since chronic disease prevalence was low $(1.0-2.6 \%)$ for those below the age of 40 years. However, $37.3 \%$ of those aged $\geq 40$ years reported having been diagnosed with one or more chronic diseases, and this proportion was higher among PWB consumers than PWWB consumers $(46.5$ v. 16.1\%). The same trend in proportions was found when examining hypercholesterolaemia, hypertension, type 2 diabetes and CHD individually by bread intake group (Table 1). Notably, diabetics in this age group obtained $38 \%$ of their total energy from bread (compared with $33 \%$ in the sample as a whole), and $88 \%$ reported PWB bread intake patterns on the recall day. In univariate logistic regression analysis, the OR of having at least one chronic condition in the PWB group as compared with the PWWB group was 4.52 (95\% CI 1.56, 13.10; $P=0.006)$. After controlling for other risk factors and possible confounders, including age group, BMI category, PAL, sex, smoking, rural/urban status, employment and total fat intake, the OR increased to $9.85(95 \%$ CI $2.64,36 \cdot 71 ; P=0 \cdot 001)$.

\section{Discussion}

In the BNS study population, the intake of the main traditional dietary staple, wholewheat bread, dropped to $14 \%$ of the total energy intake, from an estimated $50-60 \%$ in the $1960 \mathrm{~s}^{(1)}$. Concurrently, BMI for Bedouin men (about $21.3 \mathrm{~kg} / \mathrm{m}^{2}$ ) and women (about $21.4 \mathrm{~kg} / \mathrm{m}^{2}$ ) in the $1960 \mathrm{~s}$ rose to 25.0 and $26.4 \mathrm{~kg} / \mathrm{m}^{2}$, respectively, and fewer than $10 \%$ of the BNS sample reported engaging in traditional physical activities.
These changes have been accompanied by dramatic increases in chronic disease rates ${ }^{(2,11,12)}$. The replacement of wholewheat bread as the traditional dietary staple with unfortified white-flour bread was associated with a more Westernised lifestyle, characterised by urbanisation, lower bread intake, the consumption of store-bought bread, and dieting behaviours. Those in the sample who maintained the more traditional wholewheat bread intake pattern (defined as eating at least two meals per $d$ with wholewheat bread) obtained over one-third of their total energy from wholewheat bread, and had a higher energy-adjusted intake of dietary fibre and most micronutrients than those who consumed primarily white bread ( $25 \%$ of total energy), and obtained only $5 \%$ of their energy intake from wholewheat bread. Among respondents $\geq 40$ years, those with traditional PWWB intake were less likely to report having been diagnosed with chronic diseases than those with PWB intake.

The present study has a number of limitations. The crosssectional nature of the data prohibits making any causal inferences from the findings. In addition, the sample was not randomly drawn, so caution is needed when generalising the findings to the larger Bedouin population. However, the sample included a broad geographic cross-section, with sufficient numbers of both rural and urban Bedouin to enable the exploration of dietary change among these subgroups, and the low level of engagement in traditional agro-pastoral physical activities that we found is consistent with other reports in the literature ${ }^{(31)}$. Another limitation is that the chronic disease data were self-reported, and we were not able to check the participants' medical records; however, the rates of hypertension and diabetes we found were very similar to those reported from the clinical records of the Clalit Health Maintenance Organisation (HMO) to which over $85 \%$ of the Bedouin belong ${ }^{(11,12)}$.

The dietary intake data were based on one $24 \mathrm{~h}$ recall questionnaire. This dietary assessment method does not provide evidence of established dietary patterns; however, it is the standard instrument used for the nutritional surveillance of populations ${ }^{(32)}$, and has frequently been used to do initial evaluations of the effects of dietary change in populations exposed to modernisation/Westernisation processes ${ }^{(5,33-35)}$. In addition, for the main variable of interest, bread - which accounts for over $30 \%$ of the total energy intake - there tends to be less daily variability in intake in this population than there may be with other foods. The Bedouin who bake their own bread generally buy $50 \mathrm{~kg}$ sacks either of the locally ground wholewheat flour or of white flour (or have their own wheat locally ground into wholewheat flour in even larger quantities). This determines the main type of bread being consumed by the family over a long time period. For those who buy rather than bake bread, white bread is generally the only type of bread available for purchase in stores and bakeries in Bedouin communities. Therefore, given the relative consistency in this major component of the Bedouin diet, $24 \mathrm{~h}$ recall data provide a means for assessing changes in bread intake patterns, and the characteristics associated with these changes. The findings also provide insight into the potential consequences of these changes for the diet quality and health status of the population.

In the BNS, the $24 \mathrm{~h}$ recall was modified for this specific population. The modified instrument represents the first 
dietary assessment tool to be used among Negev Bedouin Arabs that systematically quantifies individual intake from common-plate meals eaten with bread on the basis of food: bread ratios derived from weighed records ${ }^{(15)}$. As such, the results provide detailed dietary intake information on a population in transition whose nutrient intakes had never been directly assessed at the individual level. The only other published dietary assessment of the Negev Bedouin was conducted over 40 years ago, and estimated individual intake by measuring household-level intake and dividing it by the number of family members ${ }^{(1)}$. This method overestimated individual intake because of unascertainable and varying numbers of extended family members and guests who also shared the meals.

In the present study, most participants reported a PWB consumption pattern. The transition away from wholewheat bread as the main dietary staple represents a Westernisation of the traditional diet, and PWB intake was also associated with markers of Westernisation/modernisation, including urbanisation, the consumption of store-bought rather than homemade bread, and dieting practices. Urbanisation has probably contributed to reduced wholewheat bread intake. In the traditional economy, the Bedouin raised grain, most of which was made into wholewheat flour for bread, and served as their main dietary staple ${ }^{(1,2)}$. It is infeasible to maintain such practices in urban settings, and we found that a much lower proportion of urban than rural residents reported having a PWWB consumption pattern, even though bulk sacks of both locally ground wholewheat and white flour are readily available in local Bedouin stores. The consumption of storebought bread is another by-product of modernisation. In this particular context, it has also fuelled the transition away from wholewheat bread intake because white-flour bread is the most readily available and affordable commercial bread product in Bedouin communities. In addition, dieting, primarily for the purpose of losing weight, is another modern phenomenon, perhaps linked to adopting more Westernised body image ideals. Dieting in the BNS sample was associated with adopting a more Westernised bread intake pattern (PWB consumption), perhaps indicating a lack of awareness of the benefits of whole-grain, high-fibre foods for maintaining a healthy weight ${ }^{(36)}$.

The food intake reported by PWB respondents was indicative of a shift away from traditional dietary patterns, not only in bread type, but in amount of bread consumed. Since PWB respondents obtained the same proportion of energy (about $62 \%$ ) from carbohydrates as PWWB respondents, the transition away from wholewheat bread resulted in a wholegrain food being replaced by refined carbohydrates.

The finding that those in the higher BMI categories $\left(>25.0 \mathrm{~kg} / \mathrm{m}^{2}\right)$ were more likely to have PWWB intake was surprising, given that the literature has tended to show increasing whole-grain intakes to be negatively associated with $\mathrm{BMI}^{(37-40)}$, although associations between refined grain intakes and BMI have not been consistent ${ }^{(39,41)}$. High whole-grain intake is often associated with lower total energy intake as part of healthier overall dietary patterns with lower fat intakes, than those found among individuals with high refined grain intakes ${ }^{(37-39)}$. In the Bedouin population, in contrast, the PWWB pattern represents maintaining traditional dietary patterns based upon very high bread intakes which provided the main source of energy for a physically demanding lifestyle. In the BNS sample, those maintaining the PWWB pattern had significantly higher absolute intakes of bread, energy, total fat, carbohydrates and protein than did PWB consumers. This suggests that PWWB consumers maintained more traditional dietary patterns in terms of both the quantity and quality of intake, despite the lower energy requirements of modern life. Thus, the combination of higher absolute energy intake, similarly sedentary PAL, and lower reported dieting behaviours among PWWB as compared with PWB consumers, may explain the association of the PWWB dietary pattern with higher BMI.

The energy-adjusted micronutrient density of the PWWB dietary intake was higher than that of the PWB intake. PWWB consumers were less likely to be below the AMDR for protein, and more likely to meet or exceed the recommended daily allowance for dietary fibre, $\mathrm{Fe}, \mathrm{Mg}, \mathrm{Zn}$ and most $\mathrm{B}$ vitamins. PWWB intakes of fibre, $\mathrm{Mg}$ and most $B$ vitamins were much higher than those generally reported in Western populations ${ }^{(42,43)}$. Nutrient intakes at these levels were recommended in the Dietary Guidelines for Americans 2005, which incorporated the Dietary Approaches to Stop Hypertension (DASH) eating plan ${ }^{(44)}$. Though the proportion of protein was lower and the proportion of carbohydrates higher than DASH goals, PWWB respondents came very close (and closer than many Western populations in which the diet has been implemented) to DASH recommendations for total fat, SFA, dietary fibre (exceeded), Fe, $\mathrm{Zn}, \mathrm{Mg}, \mathrm{K}$ and several of the B vitamins ${ }^{(45)}$, due to their high intake of wholewheat bread. In contrast, the energy-adjusted dietary fibre and micronutrient density of the diet of PWB consumers was lower than that of PWWB consumers, and in most cases fell below the recommended daily allowance.

The nutritional and health benefits of whole-grain foods have been well established. There is a large body of evidence supporting the association of whole-grain and high-dietary fibre foods with a reduced risk of the metabolic syndrome ${ }^{(39)}$, hypercholesterolaemia $^{(38)}, \mathrm{CHD}^{(46,47)}$, type 2 diabetes ${ }^{(48,49)}$, CVD mortality ${ }^{(50)}$ and several types of cancer ${ }^{(51,52)}$. A study of urban Iranians ${ }^{(39)}$ reported that those in the highest quartile of whole-grain intake were at significantly decreased risk for metabolic risk factors (for example, hypertriacylglycerolaemia, hypertension and the metabolic syndrome) than those in the lowest quartile. The results of a systematic review of prospective cohort studies of whole-grain intake and type 2 diabetes indicated that an increase of two whole-grain servings per d was associated with a $21 \%$ decrease in risk for developing type 2 diabetes ${ }^{(48)}$.

The BNS findings suggest that the Negev Bedouin are similar to other traditional and indigenous populations among whom the modernisation/Westernisation of diet and lifestyle, and urbanisation processes have been accompanied by sharp increases in chronic disease rates ${ }^{(33,53,54)}$. PWB respondents aged $\geq 40$ years were over nine times more likely to report having been diagnosed with at least one chronic disease (hypertension, hypercholesterolaemia, diabetes, CHD) than PWWB respondents after controlling for other known risk factors, including age, BMI, sex, rural/urban status, PAL and smoking. This observational finding must be viewed with caution, because of the cross-sectional nature of the study, and the multiple aspects of Negev Bedouin lifestyle aside 
from diet that have undergone change; thus, it clearly cannot be used to make causal inferences. However, the observed OR is consistent with the body of literature that has shown an association between whole-grain food intake and reduced risk for chronic diseases, and may be of public health importance for the nutrition transition that is occurring in this population.

Our findings identify a number of subgroups among Negev Bedouin that should be further studied and perhaps targeted for interventions promoting wholewheat bread and wholegrain intake. These include urban residents, those wanting to lose weight, and those with diagnosed chronic diseases. Our data suggest that efforts may be needed to improve the accessibility to and affordability of commercial wholewheat bread for Bedouin who buy rather than make bread, and who live in urban settings. The finding that middle-aged and older Bedouin (aged $\geq 40$ years) with diagnosed chronic diseases, including diabetes, were more likely to be in the group eating primarily white bread and other refined carbohydrates is noteworthy. The high bread intake (38\% of total energy) of diabetics aged $\geq 40$ years, $88 \%$ of whom were eating primarily white bread, may provide one insight into why reported rates of controlled diabetes $(\mathrm{HbA} 1 \mathrm{c}<7 \%)$ were so much lower (about 29\%) for this group than for Jewish diabetics $(47 \%)$ being treated by the same managed health care organisation $^{(11)}$. Our data suggest that middle-aged and older Bedouin adults with chronic diseases, and those doing weight-loss diets, who would most benefit from the intake of whole-grain foods, have not received this message in a way that has been effective in influencing their behaviour, and should be targeted by nutritional interventions.

As many Western societies are faced with the challenge of changing dietary habits to increase whole-grain food consumption in order to reduce chronic disease risks ${ }^{(36)}$, the challenge for public and clinical health care providers in the Bedouin community may be, instead, to reduce chronic disease risk by preserving traditional whole-grain dietary habits, in combination with other lifestyle interventions. Our observational study suggests that PWB intake is associated with a less traditional lifestyle and poorer diet quality, and, among those above the age of 40 , increased risk for chronic diseases. Thus, PWB intake may constitute a useful marker for at-risk subgroups to target for nutritional interventions. Prospective cohort and intervention studies, which take into account concurrent changes in other relevant lifestyle factors, are needed to confirm these findings.

\section{Acknowledgements}

The present study was supported by funds from the S. Daniel Abraham International Center for Health and Nutrition, Department of Epidemiology and Health Services Evaluation, Faculty of Health Sciences, Ben-Gurion University of the Negev, Israel. Manuscript preparation was supported by a post-doctoral grant from Mr Robert Arnow.

K. A.-S. contributed to the conception and design, acquisition of data, analysis and interpretation of data, drafting of the article, and revising it critically for important intellectual content; I. S. contributed to the conception and design, analysis and interpretation of data, and critical revision of the article for important intellectual content; V. K.-S., L. G. and $\mathrm{H}$. V. contributed to the analysis and interpretation of data, and critical revision of the article for important intellectual content; D. F. contributed to the conception and design, acquisition of data, analysis and interpretation of data, and critical revision of the article for important intellectual content. All authors gave final approval of the version to be published.

The authors declare that they have no conflicts of interest.

\section{References}

1. Groen JJ, Balough M, Levy M, et al. (1964) Nutrition of the Bedouins in the Negev Desert. Am J Clin Nutr 14, 37-46.

2. Abu-Saad K, Weitzman S, Abu-Rabiah Y, et al. (2001) Rapid lifestyle, diet and health changes among urban Bedouin Arabs of southern Israel. FNA 28, 45-52.

3. Marx E (2000) Land and work: Negev Bedouin struggle with Israeli bureaucracies. Nomadic People 4, 106-121.

4. Madanat HN, Troutman KP \& Al-Madi B (2008) The nutrition transition in Jordan: the political, economic and food consumption contexts. Prom Educ 15, 6-10.

5. Kuhnlein HV, Receveur O, Soueida R, et al. (2004) Arctic Indigenous Peoples experience the nutrition transition with changing dietary patterns and obesity. $J$ Nutr 124, 1447-1453.

6. Abu-Saad I (2008) Spatial transformation and indigenous resistance: the urbanization of the Palestinian Bedouin in southern Israel. Am Behav Scientist 51, 1713-1754.

7. Ben-Assa S (1964) Medical observations on 2000 Bedouin patients (article in Hebrew). Harefuah 67, 450-453.

8. Degen AA (2003) Roles of urbanized Negev Bedouin women within their households. Nomadic People 7, 108-116.

9. Fraser D, Abu-Saad K \& Abu-Shareb H (2001) The relative importance of traditional and 'modern' foods for Israeli Negev Bedouins - a population in transition. Nutr Metab Cariovasc Dis 11, Suppl. 4, 66-69.

10. Central Bureau of Statistics (2006) Profiles of Local Authorities in Israel 2006 (in Hebrew). http://www.cbs.gov.il/publications/ local_authorities2006/tab.htm

11. Cohen AD, Gefen K, Ozer A, et al. (2005) Diabetes control in the Bedouin population in southern Israel. Med Sci Monit 11, CR376-CR380.

12. Tamir O, Peleg R, Dreiher J, et al. (2007) Cardiovascular risk factors in the Bedouin population: management and compliance. IMAJ 9, 652-655.

13. Anonymous (2004) Statistical Yearbook of the Negev Bedouin, no. 2. Beer Sheva, Israel: The Center for Bedouin Studies and Development and the Negev Center for Regional Development, Ben-Gurion University of the Negev.

14. Swirski S \& Hasson Y (2006) Invisible Citizens: Israel Government Policy Toward the Negev Bedouin. Beer-Sheva, Israel: HaMachpil Ltd.

15. Abu-Saad K, Shahar DR, Abu-Shareb H, et al. (2009) Assessing individual dietary intake from common-plate meals: a new tool for an enduring practice. Public Health Nutr (epublication ahead of print version 1 May 2009).

16. Fraser D, Bilenko N, Vardy H, et al. (2008) Differences in food intake and disparity in obesity rates between adult Jews and Bedouins in southern Israel. Ethn Dis 18, 13-18.

17. Central Bureau of Statistics (2001) Statistical Abstract of Israel, no. 52, Table 2.10. Jerusalem: Central Bureau of Statistics.

18. Shahar D, Shai I, Vardi H, et al. (2003) Development of a semiquantitative food frequency questionnaire (FFQ) to assess dietary intake of multiethnic populations. Eur J Epidemiol 18, $855-861$. 
19. Wright JD, Wang CY, Kennedy-Stephenson J, et al. (2003) Dietary intake of ten key nutrients for public health, United States: 1999-2000. Adv Data 334, 1-4.

20. Subar AF, Thompson FE, Kipnis V, et al. (2001) Comparative validation of the Block, Willett, and National Cancer Institute food frequency questionnaires: the Eating at America's Table Study. Am J Epidemiol 154, 1089-1099.

21. United States Department of Agriculture (1995) Continuing Survey of Food Intakes by Individuals. Washington, DC: USDA.

22. Shai I, Rosner BA, Shahar DR, et al. (2005) Dietary evaluation and attenuation of relative risk: multiple comparisons between blood and urinary biomarkers, food frequency, and 24-hour recall questionnaires - the DEARR study. J Nutr 135, 573-579.

23. Conway JM, Ingwersen LA, Vinyard BT, et al. (2003) Effectiveness of the US Department of Agriculture 5-step multiple-pass method in assessing food intake in obese and nonobese women. Am J Clin Nutr 77, 1171-1178.

24. Shai I, Vardi H, Shahar DR, et al. (2003) Adaptation of international nutrition databases and data-entry system tools to a specific population. Public Health Nutr 6, 401-406.

25. United States Department of Agriculture, Human Nutrition Information Service (1996) Food Intake Analysis System, version 3. Houston, TX: University of Texas Health Science Center at Houston School of Public Health.

26. Pols MA, Peeters PH, Ocké MC, et al. (1997) Relative validity and repeatability of a new questionnaire on physical activity. Prev Med 26, 37-43.

27. Wareham NJ, Jakes RW, Rennie KL, et al. (2002) Validity and repeatability of the EPIC-Norfolk Physical Activity Questionnaire. Int J Epidemiol 31, 168-174.

28. Azrad A (2002) Association between physical activity, energy balance, dietary habits and heatlh-related parameters in a working population. Masters Thesis, Ben-Gurion University of the Negev.

29. Food and Agriculture Organization \& World Health Organization, United Nations University (2004) Human Energy Requirements: Report of a Joint FAO/WHO/UNU Expert Consultation, no. 1. FAO Food and Nutrition Technical Report Series. Rome: United Nations University, World Health Organization, Food and Agriculture Organization of the United Nations.

30. Otten JJ, Pitzi Hellwig J \& Meyers LD (editors) (2006) The Dietary Reference Intakes: The Essential Guide to Nutrient Requirements. Washington, DC: Food and Nutrition Board and Institute of Medicine.

31. Degen AA, Benjamin RW \& Hoorweg JC (2000) Bedouin households and sheep production in the Negev Desert, Israel. Nomadic People 4, 125-147.

32. Wright JD, Borrud LG, McDowell MA, et al. (2007) Nutrition assessment in the National Health And Nutrition Examination Survey 1999-2002. J Am Diet Assoc 107, 822-829.

33. Bersamin A, Zidenberg-Cherr S, Stern JS, et al. (2007) Nutrient intakes are associated with adherence to a traditional diet among Yup'ik Eskimos living in remote Alaska Native communities: The CANHR study. Int J Circumpolar Health 66, 62-70.

34. Kuhnlein HV \& Receveur O (2007) Local cultural animal food contributes high levels of nutrients for Arctic Canadian Indigenous adults and children. $J$ Nutr 137, 1110-1114.

35. Xu J, Eilat-Adar S, Loria C, et al. (2006) Dietary fat intake and risk of coronary heart disease: the Strong Heart Study. Am J Clin Nutr 84, 894-902.

36. Smith Edge M, Miller Jones J \& Marquart L (2005) A new life for whole grains. $J$ Am Diet Assoc 105, 1856-1860.
37. Liu S, Willett WC, Manson JE, et al. (2003) Relation between changes in intakes of dietary fiber and grain products and changes in weight and development of obesity among middleaged women. Am J Clin Nutr 78, 920-927.

38. Newby PK, Maras J, Bakun P, et al. (2007) Intake of whole grains, refined grains, and cereal fiber measured with 7-d diet records and associations with risk factors for chronic disease. Am J Clin Nutr 86, 1745-1753.

39. Esmaillzadeh A, Mirmiran P \& Azizi F (2005) Whole-grain consumption and the metabolic syndrome: a favorable association in Tehranian adults. Eur J Clin Nutr 59, 353-362.

40. Good CK, Holschuh N, Albertson AM, et al. (2008) Whole grain consumption and body mass index in adult women: an analysis of NHANES $1999-2000$ and the USDA pyramid servings database. J Am Coll Nutr 27, 80-87.

41. Gaesser GA (2007) Carbohydrate quantity and quality in relation to body mass index. J Am Diet Assoc 107, 1768-1780.

42. Shulze MB, Linseisen J, Kroke A, et al. (2001) Macronutrient, vitamin and mineral intakes in the EPIC-Germany cohorts. Ann Nutr Metab 45, 181-189.

43. Lin P, Appel LJ, Funk K, et al. (2007) The PREMIER intervention helps participants follow the Dietary Approaches to Stop Hypertension dietary pattern and the current dietary reference intakes recommendations. $J$ Am Diet Assoc 107, 1541-1551.

44. United States Department of Health and Human Services \& United States Department of Agriculture (2005) Dietary Guidelines for Americans 2005. Washington, DC: USDA. http://www.health.gov/dietaryguidelines/dga2005/document/pdf/ DGA2005.pdf

45. Mellen PB, Gao SK, Vitolins MZ, et al. (2008) Deteriorating dietary habits among adults with hypertension: DASH dietary accordance, NHANES 1988-1994 and 1999-2004. Arch Intern Med 168, 308-314.

46. Jacobs DR Jr, Meyer KA, Kushi LH, et al. (1998) Whole-grain intake may reduce the risk of ischemic heart disease death in postmenopausal women: the IOWA Women's Health Study. Am J Clin Nutr 68, 248-257.

47. Pereira MA, O'Reilly E, Augustsson K, et al. (2004) Dietary fiber and the risk of coronary heart disease: a pooled analysis of cohort studies. Arch Intern Med 164, 370-376.

48. Hu FB, Manson JE, Stampfer MJ, et al. (2001) Diet, lifestyle, and the risk of type 2 diabetes mellitus in women. $N$ Engl $J$ Med 345, 790-797.

49. de Munter JSL, Hu FB, Spiegelman D, et al. (2007) Whole grain, bran, and germ intake and risk of type 2 diabetes: a prospective cohort study and systematic review. PLoS Med 4, $1385-1395$.

50. Sahyoun NR, Jacques PF, Zhang XL, et al. (2006) Whole-grain intake is adversely associated with the metabolic syndrome and mortality in older adults. Am J Clin Nutr 83, 124-131.

51. Slavin JL (2000) Mechanisms for the impact of whole grain foods on cancer risk. Am Coll Nutr 19, 300S-307S.

52. Schatzkin A, Mouw T, Park Y, et al. (2007) Dietary fiber and whole-grain consumption in relation to colorectal cancer in the NIH-AARP Diet and Health Study. Am J Clin Nutr 85, $1353-1360$.

53. Conti K (2008) Nutrition status of American Indian adults and impending needs in view of the Strong Heart Dietary Study. $J$ Am Diet Assoc 108, 781-784.

54. Kuhnlein HV, Johns T \& the IUNS Task Force on Indigenous Peoples' Food Systems and Nutrition (2003) Northwest African and Middle Eastern food and dietary change of indigenous peoples. Asia Pacific J Clin Nutr 12, 344-349. 